\title{
$S$ sciendo Impact of selected lean management tools on work safety
}

doi:10.2478/mape-2019-0025

Date of submission to the Editor: 04/2018

Date of acceptance by the Editor: 07/2018

MAPE 2019, volume 2, issue 1, pp. 253-264

Joanna Furman ${ }^{*}$

ORCID ID: 0000-0002-8828-7186

Silesian University of Technology, Poland

\section{INTRODUCTION}

The purpose of the article is to determine the impact of selected tools of the Lean Management concept on work safety in a production plant. In the first stage identification of key threats occurring in the company was made, and then the results of the research concerning the analysis of potentially registered events were presented (the analysis covered the years 2016-2018). On this basis, in the next stage, the impact of selected tools of the Lean Management concept, implemented and applied in the enterprise on occupational safety (Kaizen, 5S, TPM) was determined. The analyses allowed to suggest the implementation of improvement measures that improve work safety. As a research method, a case study was chosen due to its the usefulness in solving problems in the field of business management as well as the methods and tools used, in order to make rational and effective decisions (Piekkari and Welch, 2011). The source of data was information provided by the analysed company and own observations.

\section{LEAN MANAGEMENT CONCEPT}

Dynamically changing conditions for running business, the development of new technologies and the increasing intensity of competition make enterprises face increasingly difficult requirements, especially as the complexity of the market environment and its instability increase uncertainty in making decisions (Grabowska and Furman, 2015). That is why companies use a variety of concepts, methods and tools that will enable them to solve problems by producing high quality products for a demanding customer.

Lean Management is a management concept that creates such a work culture in an organization that makes all participants interested in a continuous reduction of costs, raising the level of quality and shortening the delivery cycle. These activities are carried out in order to meet customer expectations and to maintain at a volatile market. This concept emphasizes the elimination of all waste. The Lean Management concept has developed based on the principles and tools of the Toyota Production System (Pawłowski et al., 2010).

The concept of Lean Manufacturing is a narrowing of the Lean Management philosophy to production processes, although in practice both terms are used interchangeably. This concept is derived from the post-war Japanese production

\footnotetext{
“ joanna.furman@polsı.pl
} 
practices (1940s). The prototype for modern Lean Manufacturing was the ToyotaProduction System, whose creators were: T. Ohno, E. Toyoda, S. Shingo (Wolniak, 2013). The term "lean" was first used in 1988 by John Krafcik in the article "Triumph of the Lean Production System", while in 1990 a group of scientists from the Massachusetts Institute of Technology: J. Womack, D. Jones and D. Roos, presented the study "The Machine That Changed the World", giving the concept of "lean" a special meaning (Womack, et al., 1991).

The basic objective of the Lean concept is the elimination of activities that do not bring added value in the company's processes, referred to as wastage (muda).Seven categories of wastage are distinguished: over-production, standstills, failures, redundant operations, improper processing, excessive stocks, redundant internal transport. The essence of the Lean concept is based on the following rules (Bendkowski and Matusek, 2013):

- defining values from the customer's point of view,

- setting all actions that create value added for the product along the value stream,

- ensuring activities that create undisturbed flow,

- application of a suction system,

- striving for perfection through the continuous elimination of emerging losses.

The Lean concept offers many tools that allow efficient and effective implementation of the "lean" management model in an enterprise, as well as for undertaking further improvement activities. The basic Lean tools include (Furman and KuczyńskaChałada, 2017):

- $5 S$ technique - a continuous process that allows you to organize your workplace by launching activities that implementation of which allows to achieve order and simultaneously improve the level of safety,

- Kaizen - concept of continuous improvement including development made in small steps in every area of the company, based on three pillars: $5 S$ technology, standardization and loss deletion,

- Value Stream Mapping (VSM) - method of processes mapping showing the flow of materials and information during the duration of a process,

- Single Minute Exchange of Die (SMED) - the aim is to shorten the time of machine retooling operations by applying standardized organizational activities that minimize the number of essential operations necessary for the conversion,

- Total Productive Maintenance (TPM) - continuous process of operating machines and devices in the enterprise, performed by maintenance workers and machine operators; the goal is to maximize the efficiency of the machine park by taking action to prevent potential failures.

It should be noted that the important element of process improvement is also the work safety aspect (Małysa et al., 2016; Małysa et al., 2017) - implemented improvements should include safe working conditions and reduce the number of potential accidents. 


\section{WORK SAFETY IMPROVEMENT WITH THE USE OF THE LEAN MANAGEMENT TOOLS}

Most of the causes of problems occurring in production processes are closely related to the course of these processes, conditions and organization of work, as well as health and safety. Lack of actions undertaken to solve these problems results in dissatisfaction of employees, causing a decrease in their involvement in work. At the enterprise level, on the other hand, it affects overall productivity, product quality and market competitiveness. The literature of the subject most often refers to the Kaizen concept, in which the $5 \mathrm{~S}$ technique is the main supporting tool used to solve problems arising from the organization of work. Good organization of work increase of safety in enterprises but all works have to build the attitudes of safe work but there are a lot of internal sources of risk in the building such new work place (Gajdzik and Grzybowska, 2013). That is why companies are trying to extend the scope of $5 S$ to the next stage - Safety (6S) - associated with safe working conditions. In this context, safety is interpreted as a foundation for the implementation of subsequent stages of the standard $5 \mathrm{~S}$ system. A company deciding to implement the $6 \mathrm{~S}$ method should adopt a strategy based on prevention, characterized by the identification of all hazards that may in the future constitute the source cause of the accident, for which improvement actions should be proposed in accordance with the particular stages of 5S. This approach will allow to create a safe workplace (Gableta et al., 2016; Gajdzik, 2014). The employer is primarily responsible for making key decisions regarding the scope of activities aimed at improving work safety. The rights and obligations of the employer and employee in the field of health and safety are regulated in Poland by the provisions of the Labour Code and detailed regulations covering this subject. The employer is obliged to provide employees with safe and ergonomic working conditions, health prevention, appropriate environmental conditions and OHS training. However, the employee is obliged to comply with all established standards and health and safety rules (Gableta et al., 2016).

Working conditions are defined as a set of all factors present in a given company, closely related to the specificity of work and the space in which it is performed. Employers 'interest in material conditions and work safety is mainly caused by the issue of employees' interests. The application of $5 \mathrm{~S}$ practices in enterprises affects the compliance with legal requirements regarding health and safety at work, as while implementation of subsequent stages of the method and setting internal standards of behaviour and implementation of the process at workplaces, employers base on the provisions contained in the safety regulations. Moreover, the $5 \mathrm{~S}$ technique includes the improvement of areas related to material conditions and work safety, and supports the implementation of various employee interests, including social and psychological aspects of comfortable human functioning in the organization. Implementation of $5 \mathrm{~S}$ or $6 \mathrm{~S}$ practices, as the main pillar of Kaizen, enables the improvement of many areas related to occupational safety, material working conditions and the realization of the interests of employees and enterprise. It introduces order, eliminates unnecessary objects and equipment, leads to discipline and self-discipline, manifested, for example, by the use of personal and collective protection (Gableta et al., 2016; Pocztowski, 1998). 


\section{ANALYSIS OF POTENTIALLY ACCIDENTAL EVENTS IN A PRODUCTION ENTERPRISE - CASE STUDY}

Potentially accidental events are events having the nature of an accident situation, but at the same time not resulting in an employee injury. In order to effectively manage them, it is necessary to determine: the cause of the event, its potential effects and plan corrective actions. In the analysed plant, in accordance with internal regulations, activities related to recording and analysing information about potentially accidental events are carried out. A procedure was developed to reduce the occurrence of potentially accidental events. It includes: the stage of event identification, stage of event analysis and the stage of implementation and assessment of corrective and preventive actions. Potentially accidental events may be reported by the operators, maintenance workers and production line managers. Some events are identified during audits of workstations carried out under the $5 S$ method. Information on potentially accidental events is placed in the register kept by the enterprise. The most frequently used quality tools are used to identify root causes of events: Ishikawa diagram, 5 Why analysis, root cause analysis. When analysing potentially incidental events, the following aspects are taken into account:

- behaviour of the employee that could lead to the occurrence of the event, e.g.: deliberate non-compliance with work procedures and regulations, improper performance of tasks, non-use of personal protective equipment, improper use of machinery and tools, neglect of threats,

- way of organizing the workplace,

- technical factors, e.g. type and condition of machinery and equipment, collective protection measures applied in the plant, condition and quality of control systems and devices signalling the threat,

- material factors related to raw materials used for production,

- work methods at the workstation where potentially accidental events occurred, including compliance with the principles of work ergonomics, access to safety instructions, equipping employees with personal protective equipment and access to such.

\section{Identification of threats in an enterprise}

In the analysed plant, due to the specificity of the processes carried out and the type of machinery and equipment used, key threats have been identified that may result in accidents at work. The categories of threats together with their potential causes are presented in Table 1. The causes of threats pose a direct threat to the life and health of employees, they are also identified as the root causes of the occurrence of potentially accidental events in the analysed enterprise. 
Table 1

Hazards and their causes in an enterprise

\begin{tabular}{|c|c|}
\hline Hazards & Causes of hazards \\
\hline Hot surfaces & $\begin{array}{l}\text { The production process uses the mass obtained as a result of heating } \\
\text { polypropylene granules and thermoforming machines are used, in the interior of } \\
\text { which there is high temperature. Machine failure and employee's inattention may } \\
\text { cause the skin to come into contact with the hot granules or the heating element } \\
\text { of the machine (as a result, it can burn naked parts of the body). } \\
\text { Machines emitting high temperature have been marked with pictograms, } \\
\text { however, there some failures may occur, as a result of which an employee may } \\
\text { touch a hot element of the machine, experiencing burns. }\end{array}$ \\
\hline $\begin{array}{l}\text { Movable } \\
\text { elements of } \\
\text { machinery }\end{array}$ & $\begin{array}{l}\text { The occurrence of an injury can occur as a result of direct human contact with } \\
\text { moving parts of machines and devices on the production line, as a result of which } \\
\text { injuries may occur, such as cuts, knocks, resulting in bruises and swelling, as well } \\
\text { as fractures. } \\
\text { The reasons for the event may be due to the employee being inattentive, e.g. } \\
\text { improper operation of the machine, lack of precautions, failure to apply personal } \\
\text { protective equipment, and poor technical condition of the machines. }\end{array}$ \\
\hline Slippery surfaces & $\begin{array}{l}\text { The cause of the hazard may be most often the moistening of the floor or spilling } \\
\text { of slippery substances on its surface, e.g. oils and lubricants used for machine } \\
\text { maintenance. As a result, employees are exposed to falls, during which they may } \\
\text { experience bruises, fractures, dislocations. }\end{array}$ \\
\hline Electric current & $\begin{array}{l}\text { Equipment and machines on the production line are powered by electricity, } \\
\text { therefore accidents related to electric shock are exposed to both operators } \\
\text { performing autonomous maintenance and maintenance workers. The risk of an } \\
\text { accident may result from non-compliance with OSH regulations, excessive use of } \\
\text { the machine or negligence of the maintenance department employees who will } \\
\text { protect the electrical wiring in the wrong way. }\end{array}$ \\
\hline $\begin{array}{l}\text { Irritating chemical } \\
\text { substances }\end{array}$ & $\begin{array}{l}\text { The threat occurs mainly on the production line and in the warehouse, where } \\
\text { substances containing harmful chemicals are used. As a result of their impact, } \\
\text { eye irritation, respiratory system and skin burns may occur. }\end{array}$ \\
\hline
\end{tabular}

Source: (own elaboration on the basis data from company).

\section{Analysis of potentially accident events}

Based on the data provided by the company, the analysis of potentially accidental events was conducted. In 2016-2018, the number of reported events amounted to 340,579 and 540 applications respectively (Fig. 1). The increase in the number of notifications in 2017 by 239 compared to 2016 resulted from the fact that employees were trained with the notification reporting system (which was a problem in previous years) and increased awareness of work safety.

When registering applications, the risk level is determined on the basis of the analysis carried out at the plant (small, medium and large risks) and the category related to the nature of the event marked with letters: $\mathrm{B}, \mathrm{O}$ or $\mathrm{T}$.

Category "B" refers to behavioural events related to improper behaviour of the employee (e.g. non-use of protective clothing, inappropriate use of tools, distraction, neglect of hazards, etc.). The category "O" is given to events of an organizational nature, resulting, for example, from the adopted working procedures (category includes, among others, lack of supervision over employees or inappropriate supervision, lack of safety instructions, improper organization of the work area, excessive work pace, etc.). Category "T" is assigned to technical events, resulting from the use of machine and tools park (e.g. damage to machine's protective cover, loosening of moving machine parts, damaged tools, failure of control systems, damage to electrical wires, etc.). 


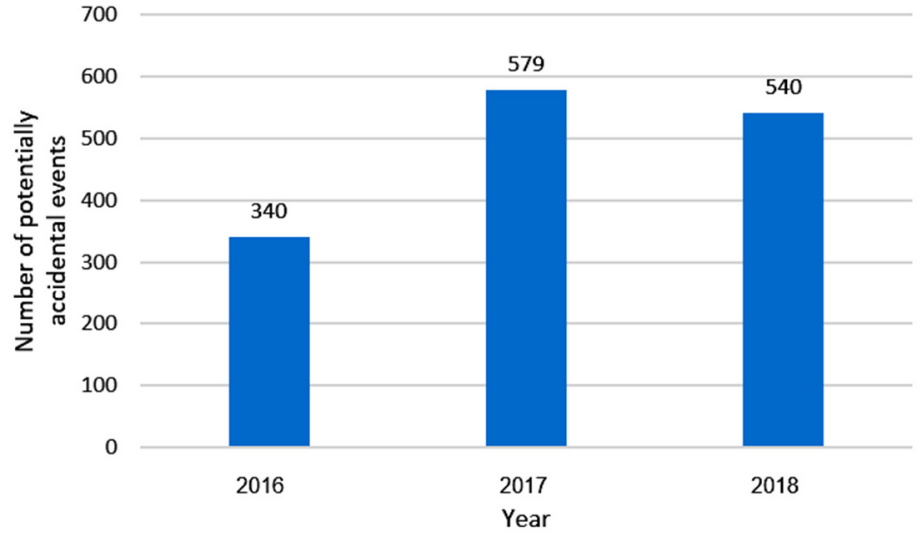

Fig. 1 Number of potentially accidental events in the company in 2016-2018

Due to the limited possibility of publishing all data from 2016-2018, the article presents detailed results only for 2018 . The analysed company provided data on potentially accidental events, however the registered data do not coincide with the statistics presented on the number of notifications - therefore only some of them were analysed. This problem stemmed from the fact that a number of events reported by employees were ultimately not considered a potential accident or were not classified as an accident at work and were subject to a different procedure.

In 2018 , out of 540 potentially accidental events reported in the company, 322 were registered. Most events (as many as 172) concerned the production line C, which clearly dominated over the remaining areas in terms of the number of these events (Fig. 2).

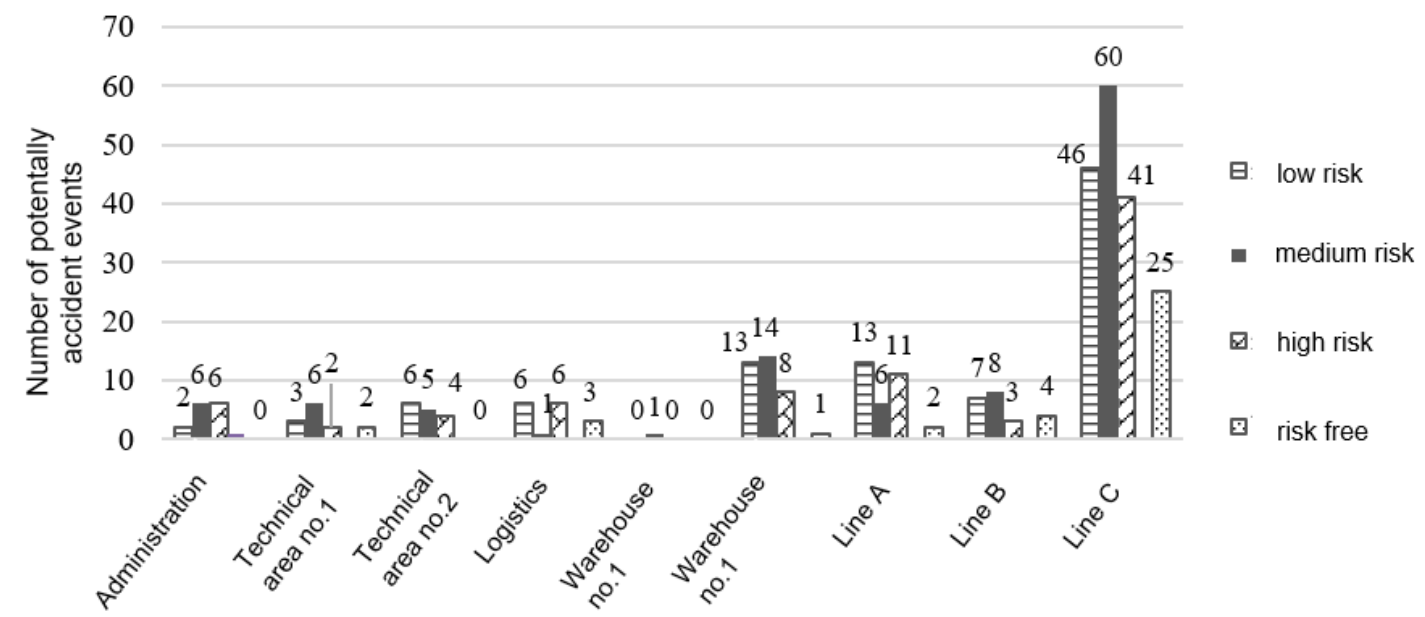

The area of identification of potentially accidental events

Fig. 2 Potentially accidental events registered in 2018 due to the type of risk and the area of registration

This means that improvement activities are necessary in this area. There were 107 events with an average risk level and 81 events with a high level of risk (which accounted for $58.4 \%$ of the total number of registered events). It is connected with the probability of an accident, therefore prophylactic measures should be applied to these events. In 2018, 96 low-risk events were registered, and no risk category was assigned to 38 events (Fig. 2). 
For 308 potentially accidental events, a category related to the nature of the event was assigned (Figure 3). The highest number of notifications concerned technical events ("T", 230), definitely less related to organizational events ("O", 57) and behavioural events ("B", 21). It should be noted that as many as 132 technical events were recorded on production line $\mathrm{C}$. These results indicate the need to undertake improvement actions aimed at improving activities within the TPM system operating in the plant (both in terms of duties performed by employees of the maintenance department and operators performing activities under Autonomous Maintenance, AM).

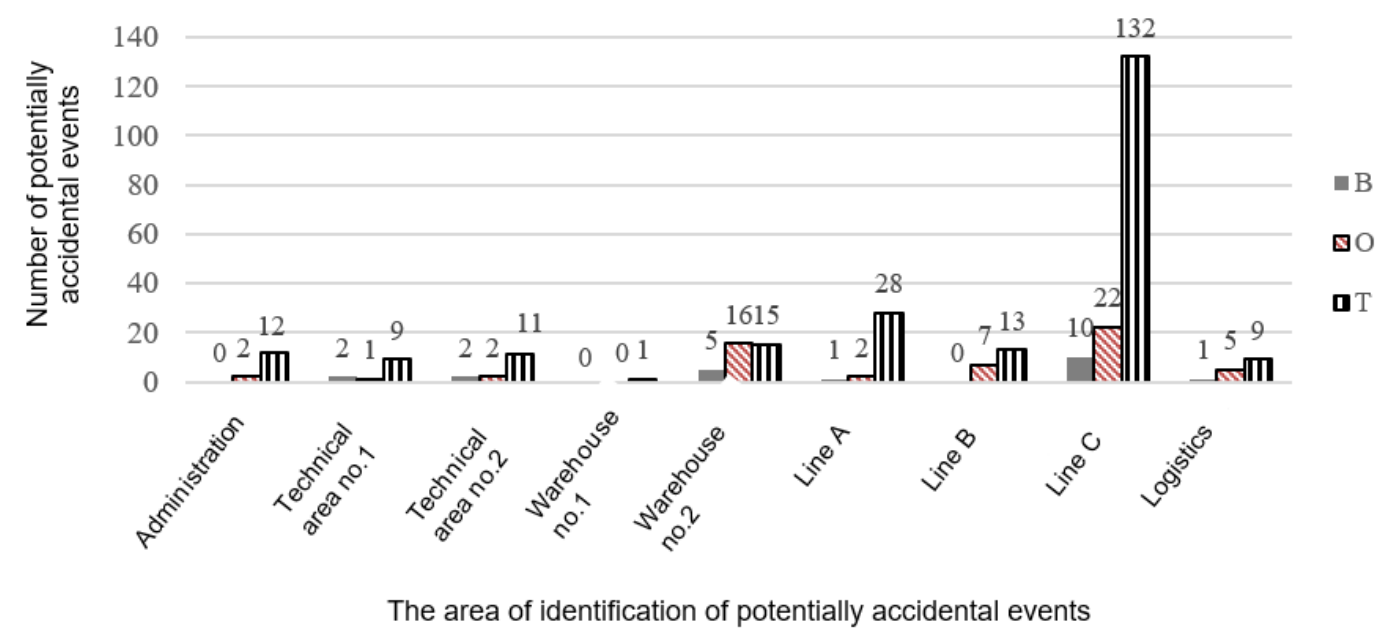

Fig. 3 Potentially accidental events registered in 2018 due to the event category and the occurrence area

In 2018, to 249 potentially accidental events a category of the effects of their occurrence was assigned. The dominant category were cuts and scratches (94 reports), 47 reports related to fractures, dislocations and sprains, while 41 concerned minor wounds and surface injuries (Fig. 4).

It should be added that the results of the analysis for 2018 show a similar problem for the entire examined period 2016-2018, both in the areas of potentially accidental events, the level of risk, and the category of events and their consequences.

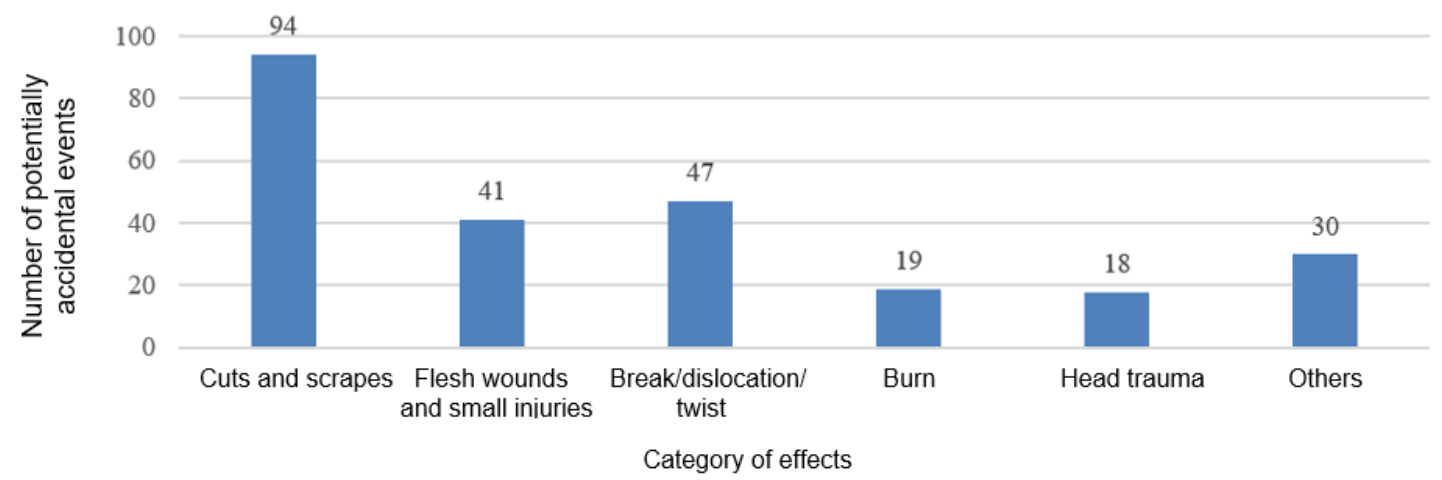

Fig. 4 Effects of reported potentially accidental events in 2018 


\section{DETERMINATION OF THE EFFECT OF SELECTED TOOLS OF LEAN CONCEPT ON WORK SAFETY IN THE ANALYSED ENTERPRISE}

The analysed company implemented solutions in the field of Lean concept, which are important from the perspective of ensuring safe working conditions, including: Kaizen, 5S, TPM, poka-yoke. Kaizen is based on such values as the employee's responsibility at the place of production, creating an orderly workplace, the ability to identify and eliminate losses, standardisation of work.

In the case of work standardization, each of the requirements is described in such a way that it is legible and understandable for employees. Standards in force in the enterprise refer to the ways of performing tasks and requirements in the scope of system operation and methods of its improvement. The standardization process includes four stages: identifying the problem, analysing the possibilities of solving it, implementing the best options for improvement and standardizing the procedure. Periodic trainings of employees are carried out to improve their skills in the area of work performed. Activities aimed at developing creative cooperation and increasing employee involvement have been introduced, such as: by working in small groups to analyse and solve problems at their place of occurrence, reporting improvements at workplaces (suggestion system). As part of the suggestion system, all implemented ideas are described in the form of standards and are subject to improvement (employees receive cash prizes). Fig. 5 shows the number of ideas submitted by employees using Kaizen cards in 2016-2018, divided into realized, considered and rejected. In 2017, 65 notifications from 95 were accepted for implementation, while in 2018 none of the 50 notifications were rejected. The most reports concerned improvements related to working methods, facilitating the performance of tasks (99 suggestions) and work efficiency (82 suggestions). 49 notifications concerned improvement of health and safety conditions, the number of which increased in the analysed period (Fig. 6).

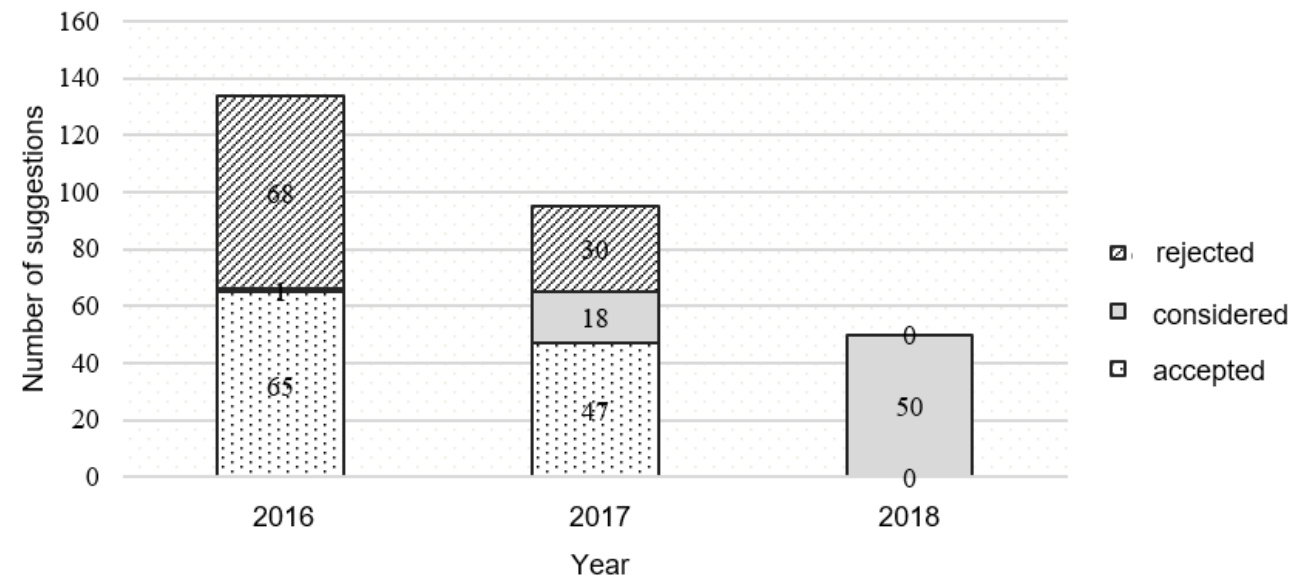

Fig. 5 The number of suggestions reported in 2016-2018

From the perspective of occupational safety, it was important to change the distribution of positions in the production hall, which was carried out in such a way as to limit losses in the form of unnecessary staff movement and excessive transport. The work stations were located in close proximity to each other, transport routes and production areas were determined using visual management. 


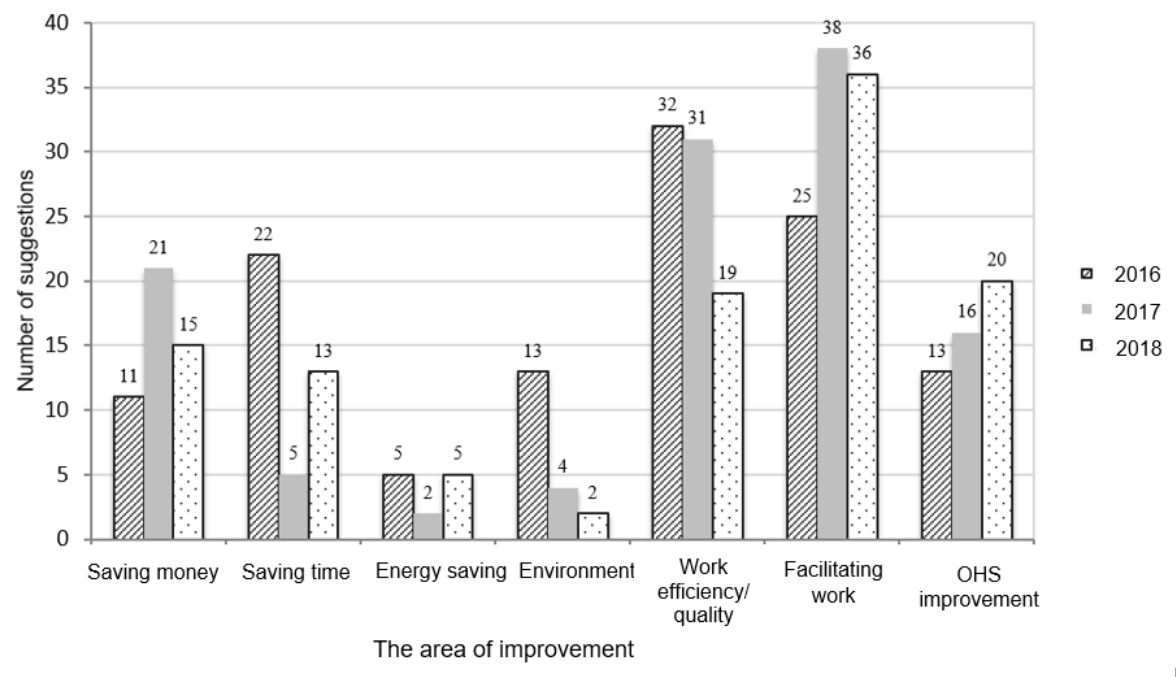

Fig. 6 The number of suggestions due to the area of proposed improvement in 2016-2018

An important element of Kaizen in the plant is the 5S method, which was introduced in the initial phase of the Lean Manufacturing system implementation. As part of the $5 \mathrm{~S}$ practices, all the tools, objects, and storage places were labelled in an appropriate manner, which allowed maintaining order in the workplace. In the workplace, there are instructions that indicate the correct and safe way to perform tasks, how to report problems and describe the principles of maintaining cleanliness. In order to maintain standards, the $5 \mathrm{~S}$ system in the plant is subject to regular auditing. In the Kaizen enterprise, the "gemba walk" principle was introduced, obliging production line managers to verify all reported problems and identify reasons for their occurrence with operators in the place of notification. Problem monitoring by managers allows to analyse and solve the problem, preventing hazardous events. The plant also implemented pokayoke solutions to prevent errors or accidents at work, e.g. production machines were equipped with sensors that emit light and sound signals, warning the operator about quality defects or machine malfunctions. After reading the signal, the operator should stop the process if necessary. This solution allows to avoid a situation in which the operator will operate a damaged machine.

The analysis of potentially accidental events showed that many of them concerned technical aspects, resulting from irregularities related to the functioning of the machinery park, which posed a threat to operators. The implemented TPM system was to prevent such events while ensuring the efficiency of the technical system. In connection with the implementation of TPM, the scope of work of maintenance workers has been increased, who analyse the condition of machines and devices, plan repair and maintenance actions, and submit notifications for effective design of production lines or the purchase of new machines. For each machine, a manual was prepared at the operator's position, which includes, among others: safe use of the machine, description of security solutions, description of activities performed by the operator, principles of daily machine inspection, failure and faults reporting. Operators were trained in the safe use of the machines they work on, as well as in the most common defects. Based on the operators' suggestions, changes are made to the applicable standards. The new standards are developed in such a way as to eliminate risks to employees and the environment. 
Summing up, it can be stated that the methods and tools of the Lean concept used in the enterprise have an impact on work safety. Many solutions reported by employees through the suggestion system or introduced into the practice in the form of standards, can reduce the number of potentially accidental events, improve the conditions related to the ergonomics of work and the way of its execution. However, the results of the analysis regarding potentially accidental events point to the necessity to undertake actions improving current standards - especially in relation to the production line $\mathrm{C}$, where the most potentially accidental events were recorded in the entire analysed period.

\section{Proposal for improvement actions}

Based on the results of the analysis and the possibilities offered by the Lean concept methods and tools used in the company, it was proposed to conduct a more detailed identification of potentially accidental events - including in the register not only the area in which the hazard occurred, but also indicating a specific workplace, where the event was observed. On this basis, it will be possible to identify areas characterized by a high level of risk, which will allow for more precise planning of preventive actions designed for a specific workplace.

Due to the occurrence of a large number of potentially accidental events of technical nature in the analysed period, improvement measures should be taken as part of the TPM system, especially in the aspect of: efficiency, selection and placement of machinery and equipment, daily machine maintenance by operators, including cleaning procedures cleaning and adjustment. Employees of the maintenance department in order to reduce the number of potentially accidental events reported and improve work safety should undergo a detailed analysis and verification: plans for machine maintenance and repairs, protocols of renovation and maintenance work, machine improvement projects aimed at increasing their reliability and safety for employees, operating instructions under AM.

In order to minimize the occurrence of behavioural events, it is necessary to systematically raise employees' awareness, mainly through health and safety trainings, training conducted in the form of workplace training (e.g. using the TWI method). In order to create appropriate attitudes in employees, it is necessary to review the audits carried out so far and introduce changes to facilitate the identification and registration of employees' behaviour that may lead to accidents at work.

In order to prevent potentially accidental events of an organizational nature, the following should be done: review the existing job instructions, develop instructions in the form of single-point lessons using visual management principles, apply competence matrices to verify the skills and knowledge of operators serving the job, and organize the workspace accordingly elimination of threats. Due to the high level of potentially accidental events reported in the analysed period, it was proposed to extend the implemented $5 S$ system to the next stage related to work safety. As a result of the implementation, the current solution is to evolve towards a more focused $6 S$ system to provide appropriate safety practices and systematically obey them. New solutions should apply to those areas in which employees reported the most suggestions, i.e. improvement of work safety, improvement of quality through implementation of ergonomic solutions, improvement of work efficiency. The extension of the existing practice requires the involvement of all employees, 
supported by health and safety services. Undertaken actions under the $6 \mathrm{~S}$ system should primarily be aimed at: elimination of threats, selection and design of technical measures that are to protect employees from threats, development of a hazard warning system, and should shape the safety culture in the plant. A plan for implementing the $6 \mathrm{~S}$ system including the following steps has been proposed:

- establishment of the implementation team and setting the work schedule,

- identification of hazard areas, analysis of reports, identification of source causes,

- identification and selection of improvement actions,

- implementation in pilot areas and throughout the plant,

- standardization and self-discipline.

Since the most potentially accidental events were of a technical nature, when developing the $6 \mathrm{~S}$ standards it is necessary to prepare procedures and instructions for safe use of machines and to develop guidelines for the maintenance department in the area of systematic machine inspections. It is particularly important to be able to quickly identify problems and take appropriate action by operators at workstations.

\section{CONCLUSION}

Within the scope of the effective in the plant registration system of the potentially accidental events, notifications from all areas of the enterprise are analysed. The activities carried out in this regard include: acceptance of the application, registration of the application, its analysis, planning and implementation of preventive actions and assessment of the effectiveness of the actions undertaken. The analysis of potentially accidental events showed that the largest number of notifications concerned technical events resulting from improper use or damage to machinery and production equipment. This indicates the need for detailed verification and implementation of improvement activities in the field of the TPM system. Nearly $60 \%$ of all registered events were high and medium risk events. It is connected with the probability of an accident, therefore prophylactic measures should be applied to these events. Solutions applied in the Lean concept applied in the plant affect work safety. However, due to the results of the analysis of potentially accidental events, the solutions used should be reviewed and the existing standards should be improved. The implementation of the $6 \mathrm{~S}$ system may prove to be an effective solution to improve safety. Implementation of $6 \mathrm{~S}$ practices may encounter many obstacles resulting from, among others, misunderstanding of goals, ignorance of employees, their resistance to changes, low level of commitment on the part of management. To prevent this, it is necessary to create conditions conducive to continuous learning, cooperation and focus on efficiency, quality and safety at work.

\section{REFEENCES}

Bendkowski, J. and Matusek, M. (2013). Logistyka produkcji. Praktyczne aspekty. Narzędzia, metody, systemy, Gliwice: Wydawnictwo Politechniki Śląskiej, pp. 33-35.

Gableta, M., Cierniak-Emerych, A. and Dziuba, S. (2016). System 5S jako podstawa doskonalenia warunków i bezpieczeństwa pracy w przedsiębiorstwie produkcyjnym. Zarządzanie i Finanse, 14(2), pp. 75-86.

Gajdzik, B. and Grzybowska, K. (2013). Internal sources of risk in building employees' attitudes of safe work in metallurgical enerprise. Metalurgija, 2 (52), pp. 285-288.

Gajdzik, B. (2014). 6S w przedsiębiorstwach produkcyjnych. Ewolucja praktyki 5S w kierunku bezpieczeństwa pracy. Problemy Jakości, 46(7-8), pp. 37-42. 
Grabowska, S. and Furman, J. (2015). Business model of steel company - focus on the innovation. In: METAL 2015: 24th International Conference on Metallurgy and Materials. Ostrava: Tanger, pp.1933.

Furman, J., and Kuczyńska-Chałada, M. (2017). The influence of Lean Manufacturing tools on the product quality in the casting process - case study. In: METAL 2017: 26th International Conference on Metallurgy and Materials. Ostrava: Tanger, pp. 2128.

Małysa, T., Nowacki, K. and Furman, J. (2016). The risk management methodology in the metallurgical enterprises. In: METAL 2016: 25th International Conference on Metallurgy and Materials. Ostrava: Tanger, pp. 1925.

Małysa, T., Nowacki, K. and Lis, T. (2017). The correlation between structure of employment and accidents at work in metallurgical enterprises. In: METAL 2017: 26th International Conference on Metallurgy and Materials. Ostrava: Tanger, pp. 2244.

Pawłowski, E., Pawłowski, K. and Trzcieliński S. (2010). Metody i narzędzia Lean Manufacturing. Materiały dydaktyczne. Poznań: Wydawnictwo Politechniki Poznańskiej, pp.13.

Piekkari, R. and Welch, C. (2011). Rethinking the Case Study in International Business and Management Research. Edward Elgar, Cheltenham, pp. 27-28.

Wolniak, R. (2013). Metody i narzędzia Lean Production i ich rola w ksztaltowaniu innowacji w przemyśle. In: R. Knosala, ed., Innowacje w Zarządzaniu i Inżynierii Produkcji. Opole: Oficyna Wydawnicza PTZP, pp. 524-525.

Womack, J.P, Jones, D.T. and Roos D. (1991). The Machine That Changed The World: The Story of Lean Production. New York: Harper Business, pp. 28-38.

Abstract. The ongoing processes in production enterprises must be constantly monitored and improved in order to meet the requirements of growing competition in the technical, technological and organizational aspects. Also, customer expectations regarding the quality of products are constantly increasing, while maintaining the lowest manufacturing costs. The analysis of the course of operations, exploited resources, materials, recharges, as well as the identification of risk and losses are the basis for improvement and optimization, leading to increase in process efficiency, as well as optimisation of organization and working conditions. There are many management methods and tools used to streamline processes. Currently, Lean Management (LM) is one of the most popular and effective concepts in this field. The primary goal of $L M$ is to eliminate activities that do not bring added value in processes, while saving resources and meeting customer requirements. The Lean concept offers many useful methods and tools that, when properly selected in the organization, implemented and used, can bring the intended results. The aim of the article is to present the results of the analysis of potentially accidental events in a production enterprise based on the identification of key threats occurring in the plant. Based on Lean Management methods and tools implemented in the company, their impact on work safety was determined.

Keywords: Lean Management tools, improvement, work safety 